\title{
Alloy Degradation Under Oxidizing-Sulfidizing Conditions at Elevated Temperatures
}

\author{
Brian Gleeson* \\ Department of Materials Science and Engineering and Metal \\ and Ceramic Sciences Program, Ames Laboratory (USDoE) \\ Iowa State University, Ames, IA 50011, USA
}

Received: September 2, 2002; Revised: September 4, 2002

\begin{abstract}
Exposure of high-temperature alloys to a low- $\mathrm{P}_{\mathrm{O}_{2}}$ oxidizing-sulfidizing environment above about $550{ }^{\circ} \mathrm{C}$ is often characterized by an initial period of protective oxidation followed by more rapid corrosion. This paper will provide a brief overview of alloy corrosion in oxidizing-sulfidizing atmospheres, with specific consideration given to the thermodynamic and kinetic aspects of the process, resulting modes of degradation, and alloy selection. The concept of a "critical microstructure" in the subsurface of the alloy as a prerequisite to initiating protective scale breakdown will also be discussed. The paper will conclude with a specific example of alloy development for the filtration of hot oxidizing-sulfidizing gases.
\end{abstract}

Keywords: sulfidation, thermodynamics, kinetic boundary, breakaway, critical microstructure

\section{Introduction}

There exist a number of high-temperature commercial processes which produce complex gaseous environments that can be both oxidizing and sulfidizing to the alloy components. These processes include oil refining, coal gasification, and fossil-fuel conversion. The resulting multi-oxidant process environments are often non-equilibrium and can vary in degree of aggressiveness. The high-temperature corrosion of metals and alloys in oxidizing-sulfidizing environments has been reviewed by Gesmundo et al. ${ }^{1}$, Stroosnijder and Quadakkers ${ }^{2}$, Stringer ${ }^{3}$, and Grabke et al. ${ }^{4}$, to name a few. From these and other reviews ${ }^{5-7}$ it can be generalized that important factors associated with oxidation-sulfidation include:

- temperature and time at temperature

- gas composition (whether sulfur is present primarily as $\mathrm{H}_{2} \mathrm{~S}$ or $\mathrm{SO}_{2}$, and presence of additional species such as $\mathrm{HCl}, \mathrm{CO}, \mathrm{H}_{2} \mathrm{O}$, or a combination of these)

- gas pressure

- downtime or dew-point corrosion

- temperature differential between the component surface and the surrounding gas

- component geometry
Due to page constraints, it is not possible to review all these factors in this paper and the reader is directed to the excellent reviews that were cited. The main aims of this review are to provide a brief treatment of the thermodynamics of oxidation-sulfidation processes and to highlight modes of degradation in relation to the thermodynamic treatment. Commercial alloys that are used in sulfur-bearing atmospheres will be identified and a case study of alloy design for the filtration of hot $\left(\sim 850^{\circ} \mathrm{C}\right)$ oxidizing-sulfidizing gases will be presented.

\section{Sulfidation as a Mode of Degradation}

Although the mechanism of sulfidation is fundamentally similar to that of oxidation, they differ both in complexity and in rate of attack. Sulfidation is more complex than oxidation due to the occurrence of a larger number of stable sulfides as compared to the oxides. The complexity is further enhanced due to the low-melting-point eutectics formed in many of the metal/sulfide systems. Examples of such eutectic temperatures are: $985^{\circ} \mathrm{C}$ for iron; $880^{\circ} \mathrm{C}$ for cobalt; and $645{ }^{\circ} \mathrm{C}$ for nickel.

The maximum temperature for long-term service of

*e-mail: bgleeson@iastate.edu

Presented at the International Symposium on High Temperature Corrosion in Energy Related Systems, Angra dos Reis - RJ, September 2002. 
metallic materials exposed to highly sulfidizing environments is generally considered to be $600-650{ }^{\circ} \mathrm{C}^{8}$. This is because the sulfidation rates of most of the major metallic constituents in conventional high-temperature alloys are generally $10^{4}-10^{6}$ times higher than their oxidation rates, depending on temperature (i.e., the activation energies are different). The sulfidation rates are generally much higher than oxidation due primarily to the higher degree of nonstoichiometry in sulfides compared to the oxides ${ }^{9}$. Large deviations from stoichiometry occur in sulfides because their lattice energies are such that point defects are easily created. A sulfide containing a high density of point defects will evidence a high diffusion rate and, correspondingly, a high growth rate. For example, the sulfides of chromium are very non-stoichiometric and, as a result, the protection from sulfidation achieved by chromium additions is less than that observed for oxidation ${ }^{10,11}$. The only metals which show superior resistance to sulfide corrosion are the refractory metals (e.g., Mo, Nb, Ta, W, V). For instance, molybdenum and niobium sulfidize at rates comparable to the oxidation rates of chromium under analogous conditions.

Strafford et al. ${ }^{12}$ were the first to suggest that refractorymetal additions should be beneficial to the sulfidation resistance of the common base metals. However, as shown by Douglass and colleagues ${ }^{14-16}$, refractory-metal sulfides provide only moderate protection when formed on a commonbase-metal alloy. One reason for this is that a refractorymetal sulfide such as $\mathrm{MoS}_{2}$ has a layered crystal structure which allows for the intercalation of foreign ions of size similar to those of the common-base metals. The intercalation of the transition-metal ions occurs in octahedral holes within the Van der Waals gap separating two loosely bound S:Mo:S sandwiches. The transition-metal ions are apparently able to diffuse at a reasonably rapid rate within the Van der Waals gap. By contrast, the diffusion of both molybdenum and sulfur does not seem to occur along the open, Van der Waals gap. Thus, $\mathrm{MoS}_{2}$ is very protective on pure Mo but becomes an ineffective barrier against the transport of transition metal ions. Aluminum, on the other hand, prefers to form the spinel $\mathrm{Al}_{0.55} \mathrm{Mo}_{2} \mathrm{~S}_{4}$ rather than an intercalation compound of $\mathrm{MoS}_{2}{ }^{17}$. Formation of $\mathrm{Al}_{0.55} \mathrm{Mo}_{2} \mathrm{~S}_{4}$ imparts significant sulfidation resistance to the alloy; however, this beneficial effect has not yet been exploited in the design of commercial sulfidation-resistant alloys and coatings.

As will be discussed in the following section, the occurrence of sulfidation under oxidizing-sulfidizing conditions depends critically on the gas composition and, in some cases, the extent of equilibria. Prolonged service of an alloy component under oxidizing-sulfidizing conditions at elevated temperatures can only really occur if sulfidation is precluded. Thus, understanding the factors leading to sulfide formation under such conditions is important to understanding and hopefully avoiding accelerated failures in service.

\section{Thermodynamics of Oxidation-Sulfidation}

The thermodynamic aspects of multi-oxidant corrosion have been discussed by Giggins and Pettit ${ }^{18}$. Often, however, the complexity of a given process environment precludes an accurate determination of which type of corrosion should predominate. In such cases, it may be necessary to conduct field-exposure tests to properly evaluate the corrosion behavior of the candidate alloys. Notwithstanding, the assumption of thermodynamic equilibrium provides a reasonable starting point for assessment.

Gas Phase Equilibria: Laboratory studies on metal and alloy corrosion under oxidizing-sulfidizing conditions typically characterize the gas mixture(s) used by the corresponding equilibrium partial pressures of oxygen $\left(\mathrm{P}_{\mathrm{O} 2}\right)$ and sulfur $\left(\mathrm{P}_{\mathrm{S} 2}\right)$. Commonly used gas mixtures employed are $\mathrm{H}_{2}-\mathrm{H}_{2} \mathrm{O}$ $\mathrm{H}_{2} \mathrm{~S}$ for producing low $\mathrm{P}_{\mathrm{O} 2} / \mathrm{P}_{\mathrm{S} 2}$ ratios and $\mathrm{SO}_{2}, \mathrm{SO}_{2}-\mathrm{O}_{2}$ or $\mathrm{SO}_{2}$-containing gases for comparatively higher $\mathrm{P}_{\mathrm{O} 2} / \mathrm{P}_{\mathrm{S} 2}$ ratios. The aggressiveness of a given environment tends to increase with decreasing $\mathrm{P}_{\mathrm{O} 2} / \mathrm{P}_{\mathrm{S} 2}$ ratio. It is interesting to note that in the 1970's and '80's most corrosion studies using $\mathrm{H}_{2}-\mathrm{H}_{2} \mathrm{O}-\mathrm{H}_{2} \mathrm{~S}$ mixtures were in the temperature range 700$1000^{\circ} \mathrm{C}$, while in the 1990 's the test temperatures generally decreased to within the range $400-700{ }^{\circ} \mathrm{C}$. The reason for this decrease is that, from a practical standpoint, no alloy is resistant to the sulfidation attack found in low $\mathrm{P}_{\mathrm{O} 2} / \mathrm{P}_{\mathrm{S} 2}$ environments at temperatures greater than about $700{ }^{\circ} \mathrm{C}$.

Important gas-phase equilibria to consider are as follows:

$$
\begin{aligned}
& \mathrm{H}_{2}+\frac{1}{2} \mathrm{O}_{2} \rightarrow \mathrm{H}_{2} \mathrm{O} \\
& \mathrm{H}_{2}+\frac{1}{2} \mathrm{~S}_{2} \rightarrow \mathrm{H}_{2} \mathrm{~S} \\
& \mathrm{O}_{2}+\frac{1}{2} \mathrm{~S}_{2} \rightarrow \mathrm{SO}_{2} \\
& 2 \mathrm{SO}_{2}+\mathrm{O}_{2} \rightarrow 2 \mathrm{SO}_{3}
\end{aligned}
$$

A more complete listing of reactions would include those involving carbon-bearing gas species (e.g., $\mathrm{CO}, \mathrm{CO}_{2}, \mathrm{COS}$, and $\mathrm{CS}_{2}$ ); however, such reactions are often - but certainly not always - less important than those given above. Under reducing conditions, as found in coal gasifiers, reactions (1) and (2) are the most relevant for determining the equilibrium $\mathrm{P}_{\mathrm{O} 2}$ and $\mathrm{P}_{\mathrm{S} 2}$, while under oxidizing conditions, as found in a pressurized fluidized bed combustor (PFBC), reaction (3) and perhaps (4) are the most relevant. Reaction (4) is important only at higher oxygen partial pressures and mod- 
erate temperatures, and it is particularly sluggish in the absence of a catalyst ${ }^{1}$. However, as shown by Stroosnijder and Quadakkers ${ }^{2}$, reaction (4) can significantly affect the gas-phase equilibria when it does occur. For instance, for a $10^{5} \mathrm{~Pa} \mathrm{SO}_{2}$ atmosphere at $800{ }^{\circ} \mathrm{C}$ it is found that $\mathrm{P}_{\mathrm{O} 2}=7.2 \times 10^{-5} \mathrm{~Pa}$ and $\mathrm{P}_{\mathrm{S} 2}=3.6 \times 10^{-5} \mathrm{~Pa}$ if reaction (4) is neglected, whereas $\mathrm{P}_{\mathrm{O} 2}=1.5 \times 10^{-6} \mathrm{~Pa}$ and $\mathrm{P}_{\mathrm{S} 2}=8.4 \times 10^{-2} \mathrm{~Pa}$ if it is considered. This means that conditions become much more sulfidizing, and hence more aggressive, with increasing extent of $\mathrm{SO}_{3}$ formation.

The quotient of the equilibrium partial pressures of the reactants and products in the above reactions is termed the equilibrium constant, $K$. In the case of reaction (1), the equilibrium constant is given as

$$
\mathrm{K}_{1}=\frac{\mathrm{P}_{\mathrm{H}_{2} \mathrm{O}}}{\mathrm{P}_{\mathrm{H}_{2}} \sqrt{\mathrm{P}_{\mathrm{O}_{2}}}}=\exp \left(\frac{-\Delta \mathrm{G}_{1}^{\mathrm{o}}}{\mathrm{RT}}\right)
$$

where $\Delta \mathrm{G}_{1}^{0}$ is the standard Gibbs free energy change for reaction (1) in typical units of $J / m o l e, R$ the gas constant and $\mathrm{T}$ the absolute temperature. The equilibrium constants for the other reactions can be found in a similar manner. By combining the equilibrium constants for reactions (1) and (2) it is found

$$
\frac{\mathrm{P}_{\mathrm{O}_{2}}}{\mathrm{P}_{\mathrm{S}_{2}}}=\left(\frac{\mathrm{K}_{2}}{\mathrm{~K}_{1}} \frac{\mathrm{P}_{\mathrm{H}_{2} \mathrm{O}}}{\mathrm{P}_{\mathrm{H}_{2} \mathrm{~S}}}\right)^{2}
$$

where, from tabulated thermodynamic data ${ }^{19}$, the ratio of the equilibrium constants is given by

$$
\frac{\mathrm{K}_{2}}{\mathrm{~K}_{1}}=\exp \left(\frac{-155,710+5.41 \mathrm{~T}}{\mathrm{RT}}\right)
$$

Figure 1 shows qualitative plots based on Eqs. 6 and 7. It is seen that the $\mathrm{P}_{\mathrm{O} 2} / \mathrm{P}_{\mathrm{S} 2}$ ratio increases with increasing temperature (for a fixed $\mathrm{P}_{\mathrm{H} 2 \mathrm{O}} / \mathrm{P}_{\mathrm{H} 2 \mathrm{~S}}$ ratio) and $\mathrm{P}_{\mathrm{H} 2 \mathrm{O}}$ (at a fixed temperature and $\mathrm{P}_{\mathrm{H} 2 \mathrm{~S}}$ ). Increasing the $\mathrm{P}_{\mathrm{O} 2} / \mathrm{P}_{\mathrm{S} 2}$ ratio increases the oxidizing potential of the gas mixture which is beneficial from the standpoint of making the alloy less prone to rapid corrosion by sulfidation.

In a more oxidizing environment in which reaction (3) is relevant, the local equilibrium at a given temperature may be defined by

$$
\mathrm{K}_{3}=\frac{\mathrm{P}_{\mathrm{SO}_{2}}}{\mathrm{P}_{\mathrm{O}_{2}} \sqrt{\mathrm{P}_{\mathrm{S}_{2}}}}
$$
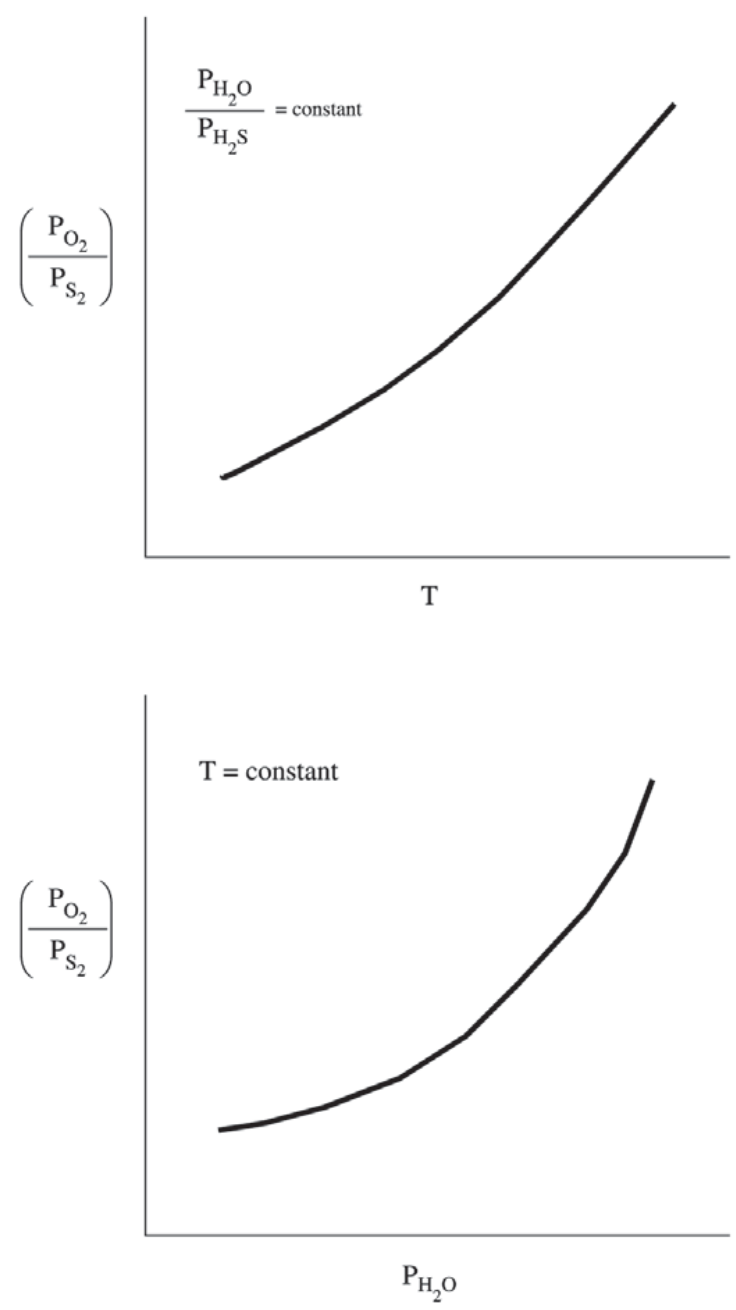

Figure 1. Dependence of $\mathrm{P}_{\mathrm{O} 2} / \mathrm{P}_{\mathrm{S} 2}$ ratio on temperature and $\mathrm{P}_{\mathrm{H} 2 \mathrm{O}}$ in an $\mathrm{H}_{2}-\mathrm{H}_{2} \mathrm{O}-\mathrm{H}_{2} \mathrm{~S}$ atmosphere.

This equation shows that that the $\mathrm{P}_{\mathrm{S} 2}$ increases with decreasing $\mathrm{P}_{\mathrm{O} 2}$ at a fixed $\mathrm{P}_{\mathrm{SO} 2}$. This is a particularly important relationship for alloys that initially form a protective oxide scale in an $\mathrm{SO}_{2}$-bearing atmosphere. If after some time the $\mathrm{SO}_{2}$ gains access to the scale/alloy interface (e.g., due to microcracking of the scale), sulfide formation is prone to occur due to the low $\mathrm{P}_{\mathrm{O} 2}$ at that interface, which would be set by the equilibrium between the oxide and the alloy. This aspect of alloy degradation in $\mathrm{SO}_{2}$-bearing atmospheres is discussed in detail by Grabke et al. ${ }^{4}$.

Perkins ${ }^{20}$ proposed a method to approximate non-equilibrium $\mathrm{P}_{\mathrm{O} 2}$ and $\mathrm{P}_{\mathrm{S} 2}$ pressures using the high-temperature gas composition, for which equilibrated $\mathrm{H}_{2} / \mathrm{H}_{2} \mathrm{O}, \mathrm{CO} / \mathrm{CO}_{2}$, and $\mathrm{H}_{2} / \mathrm{H}_{2} \mathrm{~S}$ ratios are assumed, and the equilibrium constants of the gas reactions at the cooler metal temperature. 
Such a method generally results in a lower $\mathrm{P}_{\mathrm{O} 2}$ and higher $\mathrm{P}_{\mathrm{S} 2}$ than would be predicted from equilibrium calculations over the temperature range of about $450-800{ }^{\circ} \mathrm{C}$. It is worth noting that in oxygen-lean gases containing both $\mathrm{H}_{2} \mathrm{O}$ and $\mathrm{CO}_{2}$, the $\mathrm{P}_{\mathrm{O} 2}$ is usually determined by the $\mathrm{H}_{2}-\mathrm{H}_{2} \mathrm{O}$ reaction (1) since steam is more reactive than $\mathrm{CO}_{2}$.

Gas-Metal Equilibria: Two-dimensional phase stability diagrams for a metal $\mathrm{M}$ exposed to an oxidizing-sulfidizing atmosphere can be easily determined by considering the following reactions:

$$
\begin{aligned}
& \mathrm{M}+\frac{1}{2} \mathrm{O}_{2} \leftrightarrow \mathrm{MO} \\
& \mathrm{M}+\frac{1}{2} \mathrm{~S}_{2} \leftrightarrow \mathrm{MS} \\
& \mathrm{MO}+\frac{1}{2} \mathrm{~S}_{2} \leftrightarrow \mathrm{MS}+\frac{1}{2} \mathrm{O}_{2}
\end{aligned}
$$

The equilibrium from reactions (9) and (10) define critical $\mathrm{P}_{\mathrm{O}_{2}}^{*}$ and $\mathrm{P}_{\mathrm{S}_{2}}^{*}$ values (i.e., dissociation pressures) for $\mathrm{M} /$ $\mathrm{MO}$ and M/MS equilibrium, respectively, while reaction (11) defines critical $\mathrm{P}_{\mathrm{S} 2} / \mathrm{P}_{\mathrm{O} 2}$ ratios for MS/MO equilibria. A more complete diagram may include higher-order oxides and sulphides, as well as sulfates $\left(\mathrm{MSO}_{4}\right)^{18}$. Only the simpler diagram will be discussed here since the main important points can still be made. Figure 2 shows the general construction of a phase-stability diagram. The diagram shows the stability range of a metal and its oxide and sulfide products as a function of the two principal reactants: oxygen and sulfur. A given atmosphere is defined by either equilibrium or nonequilibrium $\mathrm{P}_{\mathrm{O} 2}$ and $\mathrm{P}_{\mathrm{S} 2}$ values and would therefore be represented by a point in the stability diagram. The location of that point identifies the phase that is in stable equilibrium with that particular atmosphere. However, as shown in Fig. 3, other phases can form even if only oxide stability is predicted. This depends on the reacting gas, the $\mathrm{P}_{\mathrm{O} 2}-\mathrm{P}_{\mathrm{S} 2}$ combination, and whether the scale develops pathways for gaseous penetration (e.g., microcracks). Internal sulfidation is particularly apt to occur in $\mathrm{SO}_{2}$-containing atmospheres due to the local equilibrium dictated by reaction (3). As indicated in Fig. 3, the formation of an internal sulfide beneath an external oxide scale can only be completely avoided if

$$
\mathrm{P}_{\mathrm{SO}_{2}}<\mathrm{K}_{3} \mathrm{P}_{\mathrm{O}_{2}}^{*} \sqrt{\mathrm{P}_{\mathrm{S}_{2}}^{*}}
$$

Although phase-stability diagrams are very useful for interpreting reaction products and gaining insights into re-

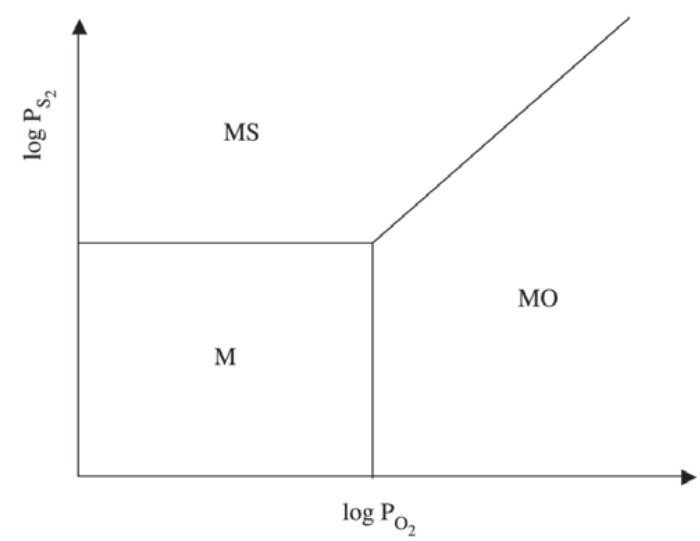

Figure 2. Schematic representation of a simple phase-stability diagram for a metal and its oxide and sulfide.

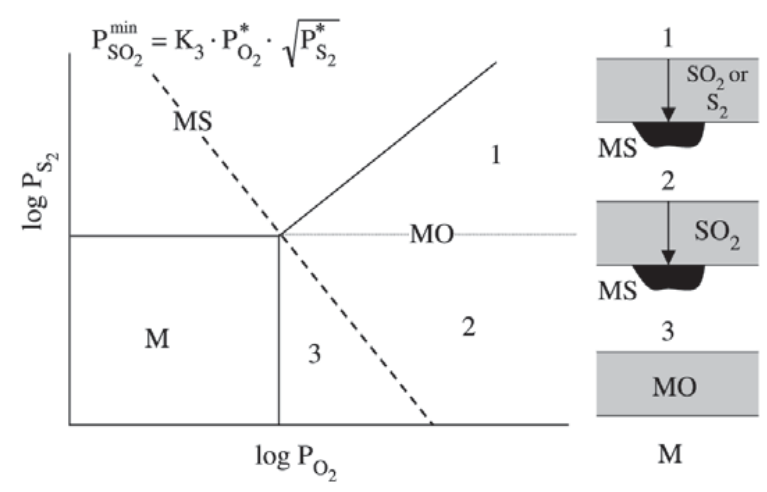

Figure 3. Application of the phase-stability diagram in identifying possible modes of attack. In this schematic diagram, the slope for $\mathrm{P}_{\mathrm{SO}_{2}}^{\min }$ is $-1 / 2$.

action pathways, they do not have any real predictive capabilities from a practical standpoint.

\section{Kinetic Boundary}

On the basis of equilibrium thermodynamics of reaction (11), the transition from sulfidation to oxidation of metal M should occur when

$$
\left(\frac{\mathrm{P}_{\mathrm{O}_{2}}}{\mathrm{P}_{\mathrm{S}_{2}}}\right)^{1 / 2}>\mathrm{K}_{11}
$$

The thermodynamic boundary separating sulfide and oxide stability in a phase stability diagram is determined by equating Eq. 13 (i.e., substituting = for $>$ ). Figure 4 shows 
the phase-stability diagram for the Type 310 stainless steel at $875^{\circ} \mathrm{C}^{2}$. Superimposed on this diagram are experimental data indicating the type of scale formed on 310 under different $\mathrm{P}_{\mathrm{O} 2}-\mathrm{P}_{\mathrm{S} 2}$ combinations. It is seen that sulfide-to-oxide transition at a given $\mathrm{P}_{\mathrm{S} 2}$ actually occurs at a higher $\mathrm{P}_{\mathrm{O} 2}$ than that predicted from equilibrium calculations. The experimentally-determined boundary is dictated by kinetic factors and, accordingly, is referred to as the kinetic boundary. For the case of the 310 stainless steel shown in Fig. 4, the actual $\mathrm{P}_{\mathrm{O} 2}$ values for the transition from chromium-sulfide to chromium-oxide formation are about three orders of magnitude higher than the equilibrium values. The kinetic factors which influence the location of the kinetic boundary include composition and surface finish of the alloy, and gas composition. Although theoretical prediction of the location of a kinetic boundary is not possible, LaBranche and Yurek ${ }^{21}$ showed that for $\mathrm{H}_{2}-\mathrm{H}_{2} \mathrm{O}-\mathrm{H}_{2} \mathrm{~S}$ gas mixtures there is a critical $\mathrm{H}_{2} \mathrm{O} / \mathrm{H}_{2} \mathrm{~S}$ ratio associated with the kinetic boundary. The value of this ratio is dictated by the competitive formation of the oxide and the faster-growing sulfide. It was found by LaBranche and Yurek that oxide formation on pure chromium at $900{ }^{\circ} \mathrm{C}$ could only occur when the area fraction of $\mathrm{Cr}_{2} \mathrm{O}_{3}$ was greater than about 0.9 in the early stages of exposure, which corresponds to $\mathrm{H}_{2} \mathrm{O} / \mathrm{H}_{2} \mathrm{~S}>10$.

\section{Breakaway Corrosion}

Exposure of a given alloy to a low $\mathrm{P}_{\mathrm{O} 2} / \mathrm{P}_{\mathrm{S} 2}$ multi-oxidant environment above about $550{ }^{\circ} \mathrm{C}$ is often characterized by an initial period of protective oxidation before the onset of more rapid corrosion. As shown schematically in Fig. 5, the breakdown of protective oxidation is usually localized - at least in the early stages - and is associated with penetration of sulfur through the oxide scale and subsequent internal sulfidation. The mechanism by which sulfur penetration occurs depends on such factors as temperature, oxide integrity, and atmosphere composition. It is generally accepted that the penetration of sulfur-bearing species occurs by molecular transport through cracks and pores which develop in the oxide scales ${ }^{22}$; although, this is not always clear or necessarily always the case.

Choi and Stringer ${ }^{23}$ postulated that penetration of the sulfur to the alloy/scale interface was a necessary, but not sufficient, criterion for oxide-scale breakdown. These authors studied the corrosion of $\mathrm{Fe}-20 \mathrm{Cr}$ alloys at $950{ }^{\circ} \mathrm{C}$ in Ar-CO- $\mathrm{CO}_{2}-\mathrm{SO}_{2}$ atmospheres having an equilibrium $\mathrm{P}_{\mathrm{O} 2}$ of $6 \times 10^{-12}$ atm and $\mathrm{P}_{\mathrm{S} 2}$ of either $10^{-5}$ or $10^{-4} \mathrm{~atm}$. A protective, $\mathrm{Cr}_{2} \mathrm{O}_{3}$-rich scale formed in both atmospheres during the initial stages of corrosion. Protective-scale growth was maintained in the lower- $\mathrm{P}_{\mathrm{S} 2}$ environment, whereas breakdown occurred after about $150 \mathrm{~h}$ in the higher- $\mathrm{P}_{\mathrm{S} 2}$ environment. Choi and Stringer proposed that the breakdown of the $\mathrm{Cr}_{2} \mathrm{O}_{3}$ scale in the higher- $\mathrm{P}_{\mathrm{S} 2}$ environment was initiated by the de-

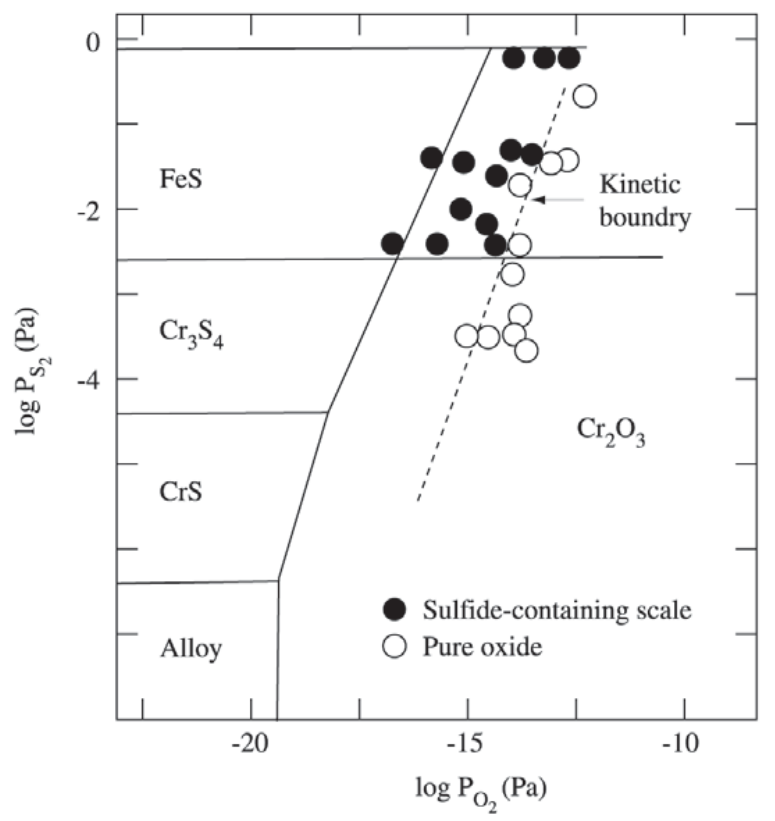

Figure 4. Thermodynamic phase-stability diagram for type 310 stainless steel at $875^{\circ} \mathrm{C}$, showing the experimentally-determined kinetic boundary ${ }^{2}$.

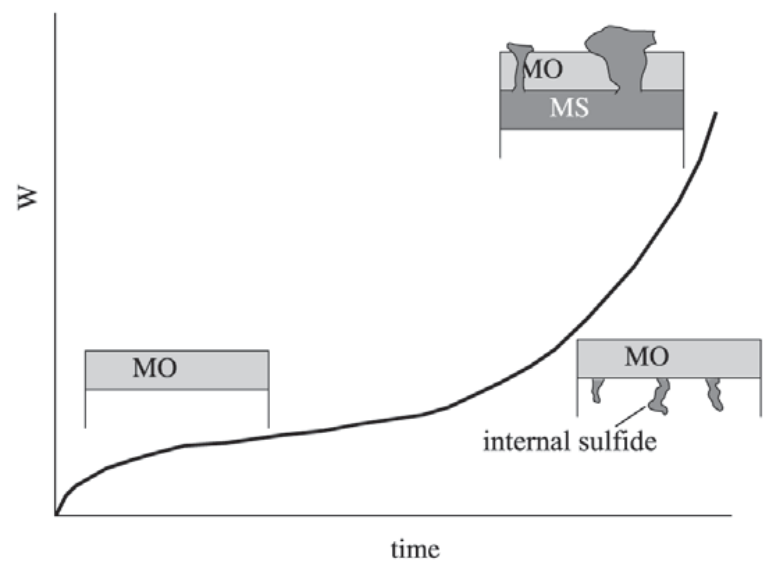

Figure 5. The usual degradation sequence leading to breakaway corrosion under oxidizing-sulfidizing conditions.

velopment of a critical microstructure in the subsurface of the alloy. The critical microstructure corresponded to a relatively coarse distribution of internal chromium-sulfide precipitates which intersected the alloy/scale interface. It was proposed that not only did the internal sulfides tie-up the chromium, but their subsequent oxidation resulted in a po- 
rous and, hence, permeable oxide. Stringer ${ }^{3}$ later extended the concept of a critical microstructure initiating scale breakdown to other multi-oxidant environments.

\section{Alloy Selection for Aggressive Oxidizing- Sulfidizing Conditions}

As noted in the Introduction, numerous commercial processes operate at temperatures exceeding about $500{ }^{\circ} \mathrm{C}$ and under conditions that are both oxidizing and sulfidizing to the metallic components. For example, a coal-gasification atmosphere may have a $\mathrm{P}_{\mathrm{O} 2}$ of $10^{-18}$ atm and a $\mathrm{P}_{\mathrm{S} 2}$ of $10^{-6} \mathrm{~atm}$ at $850{ }^{\circ} \mathrm{C}{ }^{5}$. Under such conditions, sulfidation is the principal type of corrosion; although, there may be a complex interplay with oxidation and chloridation ${ }^{24}$. Commercially available alloys that are typically used to resist degradation under oxidizing-sulfidizing conditions are primarily chromia formers. It is noted, however, that high-nickel chromia-forming alloys, such as alloy 600 (mainly 72Ni$16 \mathrm{Cr}-8 \mathrm{Fe}$ ), are particularly susceptible to rapid sulfidation attack at temperatures above $645{ }^{\circ} \mathrm{C}$ and under highly sulfidizing conditions owing to the formation of a liquid corrosion product. (Note that all compositions will be given in weight percent.) The melting temperature of the sulfide scale generally increases with increasing $\mathrm{Fe}$ and $\mathrm{Cr}$ contents ${ }^{25}$, and alloys containing $\geq 25 \mathrm{Cr}$ and $\leq 20 \mathrm{Ni}$ are considered to be safe from liquid-sulfide formation under most practical conditions. Thus, alloys such as the Types 309 and 310 stainless steels offer reasonable sulfidation resistance; although, the tendency of these alloys to form the embrittling sigma phase may be a limitation. If this is the case, and if the sulfidizing conditions are not too severe, an alloy such as Haynes 556 (mainly $31 \mathrm{Fe}-22 \mathrm{Cr}-20 \mathrm{Ni}-18 \mathrm{Co}$ ) may be a suitable alternative. For more severe conditions, cobalt-rich HR-160 (mainly 37Ni-28Cr-30Co-2.75Si) or 188 (mainly $37 \mathrm{Co}-22 \mathrm{Cr}-20 \mathrm{Ni}-14 \mathrm{~W}$ ) may be suitable alternatives. The relatively high silicon content in HR-160 confers sulfidation resistance provided the $\mathrm{P}_{\mathrm{O} 2}$ in the process environment is sufficiently high for $\mathrm{SiO}_{2}$ to be stable, which is the norm rather than the exception. The sulfidation resistance of HR160 is also benefited by the presence of a high cobalt content. High cobalt levels in nickel-base alloys reduce both the rate of sulfur diffusion in the matrix and the risk of $\mathrm{Ni}$ $\mathrm{Ni}_{3} \mathrm{~S}_{2}$ eutectic formation at $645^{\circ} \mathrm{C}$. Moreover, $\mathrm{Lai}^{26}$ showed that cobalt-base superalloys, such as alloy 188 , are more resistant to sulfidation attack than the Ni- and Fe-Ni-base superalloys when exposed to atmospheres having $\mathrm{P}_{\mathrm{O} 2} \leq 3 \times 10^{-17}$ atm and $\mathrm{P}_{\mathrm{S} 2} \leq 4 \times 10^{-6}$ atm over the temperature range $760-982^{\circ} \mathrm{C}$.

Diffusion aluminide coatings (e.g., Alonizing ${ }^{\mathrm{TM}}$ ) have been used in practice to reduce the sulfidation attack of various types of steels, including stainless steels. For the most part, however, such coatings have been restricted to smaller components $^{27}$. The long-term effectiveness of aluminide coatings is also questionable. For instance, after reviewing results from ten years of field trials under a variety of oxidizing-sulfidizing conditions, Bakker and Stringer ${ }^{6}$ concluded that diffusion coatings cannot be relied upon to provide long-term protection ( $>10$ years).

Finally, it is worth noting that oxidation of a component in a clean oxidizing environment prior to exposure to a more aggressive sulfur-bearing environment frequently fails to prevent subsequent rapid attack due to sulfidation after longterm exposures; however, it is generally beneficial in delaying breakdown. It is usually found that the duration of protection provided by a pre-formed oxide depends on the substrate alloy composition. For instance, Wright et al. ${ }^{28}$ showed that a pre-formed $\mathrm{Cr}_{2} \mathrm{O}_{3}$ scale on a Fe-25Cr-20Ni alloy is considerably inferior to that on a Fe-25Cr alloy when subsequently exposed to an oxidizing/sulfidizing environment. The $\mathrm{Cr}_{2} \mathrm{O}_{3}$ scale on the $\mathrm{Fe}-25 \mathrm{Cr}-20 \mathrm{Ni}$ alloy contained high levels of iron, whereas, for reasons that were not identified, the scale on the $\mathrm{Fe}-25 \mathrm{Cr}$ alloy was relatively free of iron. For both alloys, however, breakdown of the pre-formed $\mathrm{Cr}_{2} \mathrm{O}_{3}$ scales eventually occurred. Stott et al. ${ }^{29}$ showed that breakdown of pre-formed chromia and alumina scales in high- $\mathrm{P}_{\mathrm{S} 2}, \mathrm{H}_{2}-\mathrm{H}_{2} \mathrm{O}-\mathrm{H}_{2} \mathrm{~S}$ atmospheres is associated with the development of sulfide channels through the scales. The preformed alumina scales were found to provide significantly longer protection than the chromia scales.

\section{Case Study of Alloy Design for the Filtra- tion of Hot Oxidizing-Sulfidizing Gases}

Advanced power generating systems involving the pressurized fluidized bed combustion (PFBC) process require in their design the use of a robust hot gas filter material that possesses adequate corrosion resistance and strength ${ }^{30}$. The filter must remove abrasive/corrosive "flyash" particulate from the hot (typically about $850^{\circ} \mathrm{C}$ ) oxidizing-sulfidizing combustion gas of relatively high $\mathrm{P}_{\mathrm{O} 2} / \mathrm{P}_{\mathrm{S} 2}$ to protect the gas turbine generator located downstream of the PFBC combustion zone. Current technology uses an array of multiple ceramic cylindrical "candle" filters to provide a copious amount of filtration area. However, the current ceramic filters appear to be too brittle to withstand typical operating conditions and procedures ${ }^{31,32}$. As a result, porous metal filters are being developed and considered as alternatives for improving filter reliability and durability.

The use of metallic filters will need to rely on the formation and preservation of a slow-growing $\mathrm{Al}_{2} \mathrm{O}_{3}$ scale to protect the base metal from the surrounding environment and to ensure prolonged filtering capability. Healing or reformation of the alumina scale can occur in the event of scale cracking or spallation if a sufficient amount of aluminum is available for oxidation at the alloy surface. However, the 
very small size of the alloy powders comprising the filter places a practical limit on the reservoir of aluminum and, hence, on the duration of sustained alumina-scale growth. Eventually, the aluminum content in the alloy will deplete below a level necessary for chemical equilibrium between the alloy and the alumina scale. At this point, "chemical" breakdown of the alumina scale results and formation of less protective oxides of the base metal would ensue ${ }^{33}$.

Metallic filters based on the $\mathrm{Fe}_{3} \mathrm{Al}$ (iron aluminide) intermetallic compound have been developed as an alternative material for application in hot gas filters. Compared with $\mathrm{SiC}$ and $\mathrm{Al}_{2} \mathrm{O}_{3}$ filter materials, the iron aluminide filters offer a slight improvement in strength and resistance to thermal shock at the anticipated PFBC operating temperature of $850{ }^{\circ} \mathrm{C}$. Unfortunately, the brittle properties of the iron aluminides at ambient temperature are similar to ceramics and their strength at $850{ }^{\circ} \mathrm{C}$ is not sufficient to resist creep elongation. A Ni-Cr-Al-Fe ( Ni-16Cr-4.5Al-3Fe) filter material that was recently developed at Ames Laboratory appears to offer significant benefits over both the ceramic and iron aluminide materials ${ }^{30}$. In a cast form, the $\mathrm{Ni}-\mathrm{Cr}$ Al-Fe alloy has been shown to be able to maintain a nearly equivalent resistance to corrosion as the iron aluminide in initial sulfidizing/oxidizing corrosion tests at $850{ }^{\circ} \mathrm{C}$ for up to $1,000 \mathrm{~h}$. Also, the $850{ }^{\circ} \mathrm{C}$ yield strength of the porous sintered Ni-Cr-Al-Fe material was observed to be at least six times that of the iron aluminides, while maintaining excellent room-temperature ductility.

To further improve the oxidation-sulfidation resistance of this Ni-Cr-Al-Fe alloy, additional Al was added to enhance formation of the protective $\mathrm{Al}_{2} \mathrm{O}_{3}$ scale and to increase the reservoir of $\mathrm{Al}$ for sustained growth of the $\mathrm{Al}_{2} \mathrm{O}_{3}$ scale, which in turn, would extend filter life. Two new Ni-Cr-AlFe alloys consisting of up to three times the Al content relative to the base Ni-Cr-Al-Fe alloy were developed and tested. The corrosion resistance of these aluminum-enriched alloys was evaluated, in both "as-cast" and "pre-oxidized" conditions, utilizing an oxidizing-sulfidizing gas environment designed to simulate a typical PFBC process. The samples were exposed to a flowing $\mathrm{N}_{2}-13 \mathrm{CO}_{2}-10 \mathrm{H}_{2} \mathrm{O}-4 \mathrm{O}_{2}-$ $250 \mathrm{ppm} \mathrm{SO}$ (in vol.\%) gas mixture at $850{ }^{\circ} \mathrm{C}$ for $1,000 \mathrm{~h}$, with the samples being cooled to room temperature every $250 \mathrm{~h}$ to record their weight change. Figure 6 compares the corrosion test results of the various bulk alloys.

Based on these corrosion test results, the alloy containing twice the aluminum content as the Ni-Cr-Al-Fe base alloy was selected as a viable filter alloy and was atomized using the Ames Laboratory high pressure gas atomizer for the purpose of further testing in filter form. Figure 7 shows the weight-change results for both the as-atomized and the pre-oxidized bulk and porous sintered samples. As can be seen, the weight change experienced by the porous samples were significantly higher than the bulk samples, primarily

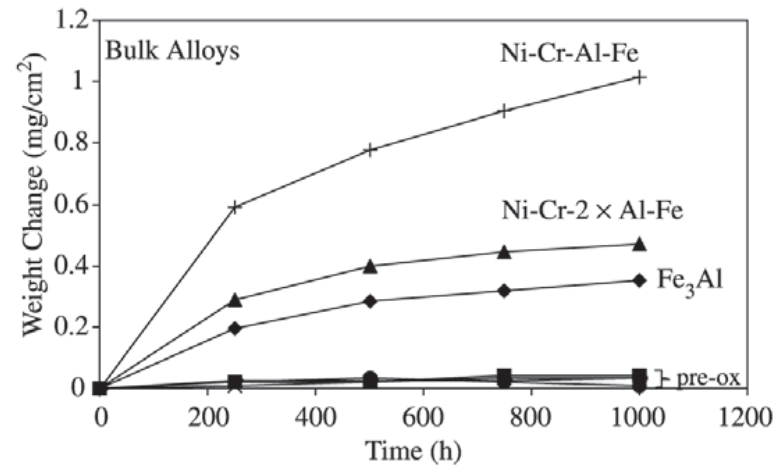

Figure 6. Corrosion test results of as cast and pre-oxidized bulk alloys exposed to $\mathrm{N}_{2}-13 \mathrm{CO}_{2}-10 \mathrm{H}_{2} \mathrm{O}-4 \mathrm{O}_{2}-250 \mathrm{pm} \mathrm{SO}$ (vol. \%) gas for $1,00 \mathrm{~h}$ at $850^{\circ} \mathrm{C}$.

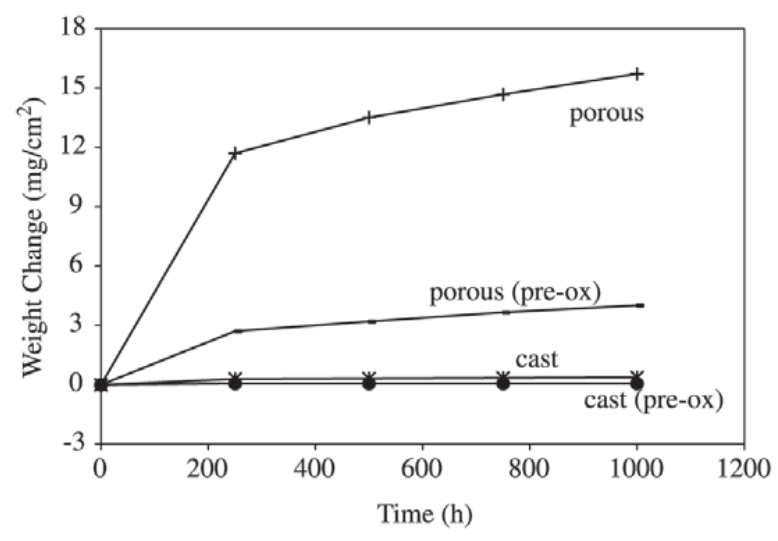

Figure 7. Corrosion test results of Ni-Cr-2xAl-Fe as cast and sintered porous samples to $\mathrm{N}_{2}-13 \mathrm{CO}_{2}-10 \mathrm{H}_{2} \mathrm{O}-4 \mathrm{O}_{2}-250$ ppm $\mathrm{SO}_{2}$ (vol. \%) gas for $1,000 \mathrm{~h}$ at $850^{\circ} \mathrm{C}$.

due to the increased surface area of the porous sample exposed to the corrosive gas (i.e., only the gross dimensional surface area was considered for the porous sample). However, the pre-oxidizing treatment remained extremely beneficial for limiting the weight change of the porous sintered $2 \times \mathrm{Al}$ sample, relative to the as-atomized porous sample.

Cross-sectional SEM images of the sintered powders after corrosion testing from both the "as cast" or "pre-oxidized" state are shown in Fig. 8. The images reveal that a continuous protective oxide layer developed on powders of sufficient size and that the oxide layer did not jeopardize the inter-particle bond that developed during the sintering cycle prior to testing. However, it is further revealed that powders less than about $15 \mu \mathrm{m}$ in diameter had a limited reservoir for sustaining alumina scale growth throughout the $1,000 \mathrm{~h}$ test, as indicated by the fact that such powders underwent extensive attack (i.e., some were through-cor- 


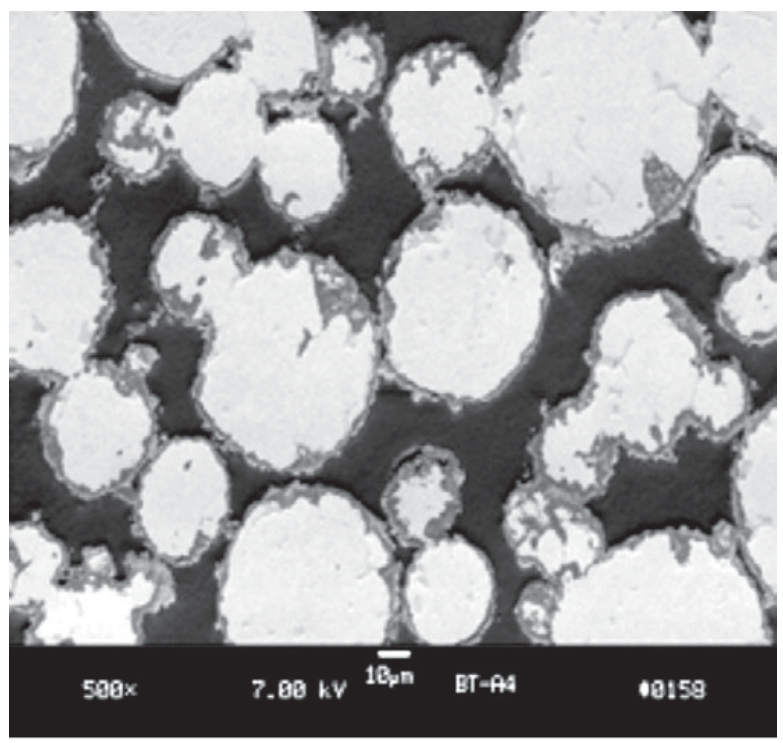

a)

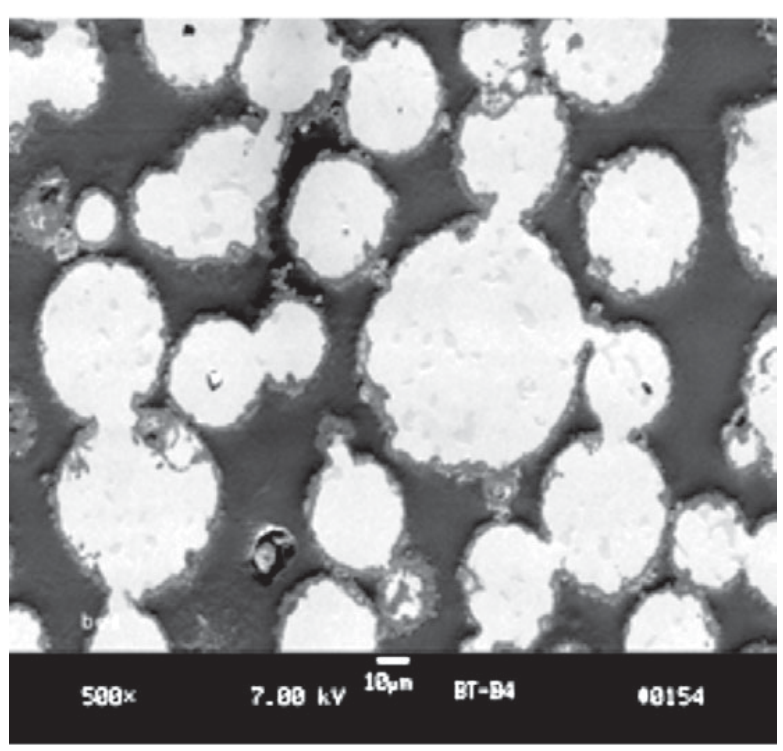

b)

Figure 8. SEM micrographs of a) "as cast"; b) "pre-oxidized" Ni$\mathrm{Cr}-2 \times \mathrm{Al}-\mathrm{Fe}$ sintered powder after corrosion testing for $1,000 \mathrm{~h}$ at $850{ }^{\circ} \mathrm{C}$.

roded). Comparing the SEM images in Fig. 8, it is seen that the pre-oxidized sintered sample experienced the least degree of attack in terms of the depth and frequency of the corrosion penetration.

With respect to the manufacturing of metallic hot gas filters, it was therefore found that doubling the alloy aluminum content did not hinder the sintering or ductility of a thin porous sintered sheet, as demonstrated previously with the baseline Ni-Cr-Al-Fe alloy ${ }^{30}$. The Ni-Cr- $2 \times \mathrm{Al}-\mathrm{Fe}$ alloy also demonstrated the ability to be joined using conventional resistance spot welding techniques. This will become particularly important when joining long seams of full length tubes to form thin-walled metallic filters for in-situ prototype testing that is planned for the next phase of the alloy-development program.

\section{Acknowledgement}

Support for the hot gas filters research is received from DOE-Fossil Energy through Ames Laboratory contract no. W-7405-Eng-82 and is gratefully acknowledged.

\section{References}

1. Gesmundo, F.; Young, D.J.; Roy, S.K. High Temp. Mater. Proc., v. 8, p. 149, 1989.

2. Stroosnijder , M.F.; Quadakkers, W.J. High Temp. Technol., v. 4, n. 141, 1986.

3. Stringer, J. High-Temperature Oxidation and Sulphidation Processes, J.D. Embury (Ed.), Pergamon Press, New York, p. 257-275, 1990.

4. Grabke, H.J.; Lobnig, R.; Papaiacovou, P. Selected Topics in High Temperature Chemistry: Defect Chemistry of Solids, Ø. Johannesen and A.G. Andersen (Eds.), Elsevier, New York, p. 263-289 1989.

5. Natesan, K. Corrosion, v. 41, n. 646, 1985.

6. Bakker, W.T.; Stringer, J. Mater. High Temp., v. 14, p. 101, 1997.

7. Stott, F.H.; Norton, J.F. Mater. High Temp., v. 14, p. 132, 1997.

8. Lai, G.Y. J. Chin. Corr. Eng., v. 10, p. 70, 1996.

9. Mrowec, S.; Przybylski, K. Oxid. Met., v. 23, p. 107, 1985.

10. Rau, H. J. Less-Common Metals, v. 55, p. 205, 1977.

11.Young, D.J.; Smeltzer, W.W.; Kirkaldy, J.S. J. Electrochem. Soc., v. 120, p. 1221, 1973.

12. Strafford, K.N.; Winstanley, G.R.; Harrison, J.M. Werkst. Korros., v. 25, p. 187, 1974.

13. Gleeson, B.; Douglass, D.L.; Gesmundo, F. Oxid. Met., v. 31, p. 209, 1989.

14. Gleeson, B.; Douglass, D.L.; Gesmundo, F. Oxid. Met., v. 33, p. 425, 1990.

15. Chen, M.F.; Douglass, D.L.; Gesmundo, F. Oxid. Met., v. 31, p. 237, 1989.

16. Wang, G.; Carter, R.V.; Douglass, D.L. Oxid. Met., v. 32, p. $273,1989$.

17. Gleeson, B.; Douglass, D.L.; Gesmundo, F. Oxid. Met., v. 34, p. 123, 1990.

18. Giggins, C.S.; Pettit, F.S. Oxid. Met., v. 14, p. 363, 1980.

19. Gaskell, D.R. Introduction to Metallurgical Thermody- 
namics, $2^{\text {nd }}$ Edition, McGraw-Hill, New York 1981.

20.Perkins, R.A. Materials for Syngas Coolers, EPRI Report AP-2518, August, 1982.

21. LaBranche, M.H.; Yurek, G.J. Oxid. Met., v. 28, p. 73, 1987.

22. Meier, G.H. Mater. Sci. Eng. A, A120, v. 1, 1989.

23. Choi, S.-H.; Stringer, J. Mater. Sci. Eng., v. 87, p. 237 1987.

24. Bakker, W.T. Mater. High Temp., v. 14, p. 197, 1997.

25. Smith, G.D. in: Corrosion/97, National Association of Corrosion Engineers, Houston, TX, Paper 5241997.

26. Lai, G.Y. High Temperature Corrosion in Energy Systems, M.F. Rothman (Ed.), The Metallurgical Society of AIME, Warrendale, PA, p. 227, 1985.

27. Tillack, D.J.; Guthrie, J.E. Wrought and Cast Heat-Resistant Stainless Steels and Nickel Alloys for the Refining and Petrochemical Industries, Nickel Development Institute, Toronto, Technical Series, n. 10, p. 71, 1998.

28. Wright, I.G.; Srinivasan, V.; Vedula, K.M. Mater, High
Temp., v. 11, p. 159, 1993.

29. Stott, F.H.; Chong, F.M.F.; Stirling, C.A. High Temperature Corrosion in Energy Systems, M.F. Rothman (Ed.), The Metallurgical Society of AIME, Warrendale, PA, p. 253, 1985.

30. Terpstra, R.L.; Anderson, I.E.; Gleeson, B. "Development of Metallic Hot Gas Filters," in Advances in Powder Metallurgy and Particulate Materials, MPIFAPMI, Princeton, NJ, v. 8, p. 84, 2001.

31. Oakley, J.E.; Lowe, T.; Morrel, R.; Byrne, W.P.; Browm, R.; Stringer, J. Mater. High Temp., v. 14, p. 301, 1997.

32. Alvan, M.A. Proc. $2^{\text {nd }}$ International Conference on HeatResistant Materials, K. Natesan, et al. (Eds.), ASM International, Materials Park, OH, p. 525, 1995.

33. Gleeson, B. "High-Temperature Corrosion of Metallic Alloys and Coatings," in Corrosion and Environmental Degradation, Vol. II: Volume 19 of the Materials Science and Technology Series, ed. M. Schütze (Weinheim, Germany: Wiley-VCH), p. 173, 2000. 